\title{
Morteza Garavand. « Tābut-e sangi makshufeh az rustāi Dastak Uliā, Sar-e Pul-e Zohāb, Kermānshāh / Stone Coffins discovered in the village of Dastak-e Ulia, Preliminary Report »
}

\section{Rémy Boucharlat}

\section{(2) OpenEdition}

\section{Journals}

Édition électronique

URL : http://journals.openedition.org/abstractairanica/46973

DOI : 10.4000/abstractairanica.46973

ISBN : 1961-960X

ISSN : 1961-960X

Éditeur :

CNRS (UMR 7528 Mondes iraniens et indiens), Éditions de l'IFRI

\section{Référence électronique}

Rémy Boucharlat, « Morteza Garavand. «Tābut-e sangi makshufeh az rustāi Dastak Uliā, Sar-e Pul-e Zohāb, Kermānshāh / Stone Coffins discovered in the village of Dastak-e Ulia, Preliminary Report » », Abstracta Iranica [En ligne], Volume 37-38-39 | 2018, document 63, mis en ligne le 30 décembre 2018 , consulté le 29 septembre 2020. URL : http://journals.openedition.org/abstractairanica/46973 ; DOI : https://doi.org/10.4000/abstractairanica.46973

Ce document a été généré automatiquement le 29 septembre 2020

Tous droits réservés 
Morteza Garavand. « Tābut-e sangi makshufeh az rustāi Dastak Uliā, Sar-e Pul-e Zohāb, Kermānshāh / Stone Coffins discovered in the village of Dastak-e Ulia, Preliminary Report »

Rémy Boucharlat 


\section{RÉFÉRENCE}

Morteza Garavand. « Tābut-e sangi makshufeh az rustāi Dastak Uliā, Sar-e Pul-e Zohāb, Kermānshāh / Stone Coffins discovered in the village of Dastak-e Ulia, Preliminary Report », Pazhuhesh-ha Zagros (Journal of Zagros Research), 2, Nos. 2 \& 3, 2014 [2015], p. 97-103, résumé anglais.

1 Deux sarcophages en pierre de forme trapézoïdale ont été découverts brisés en 2013 au cours de travaux de construction d'une maison dans le district de Sar-e Pol-e Zohab, province de Kermanshah. Ils sont suffisamment conservés pour être mesurés, respectivement $151 \times 70 \mathrm{~cm}$ et $134 \times 69 \mathrm{~cm}$, avec un fond épais de $13 \mathrm{~cm}$. De tels objets sont fréquents à l'époque parthe dans tout l'ouest de l'Iran, mais ils sont presque toujours en terre cuite. Ceux-ci sont en calcaire, comme les sarcophages, trouvés fortuitement à Suse par M. Kaboli en 1988 et par M. Rahbar en 1995; ces trois sarcophages de Suse sont différents, de plan anthropoïde (cf. Boucharlat \& Haerinck 2011, Tombes d'époque parthe à Suse, p. 47-49). L'A, qui n'a pas pu étudier les deux sarcophages dans leur contexte à Dastak-e Ulia, ne décide pas de la date, époque parthe ou sassanide.

\section{AUTEURS}

RÉMY BOUCHARLAT

UMR 5133 CNRS-Université de Lyon 